\title{
miR393 contributes to the embryogenic transition induced in vitro in Arabidopsis via the modification of the tissue sensitivity to auxin treatment
}

\author{
Anna M. Wójcik ${ }^{1} \cdot$ Małgorzata D. Gaj ${ }^{1}$
}

Received: 20 February 2016/ Accepted: 18 March 2016/Published online: 4 April 2016

(c) The Author(s) 2016. This article is published with open access at Springerlink.com

\begin{abstract}
Main conclusion miR393 was found to control embryogenic transition in somatic cells in Arabidopsis via control of the TIR1 and $A F B 2$ auxin receptors genes of the F-box family.
\end{abstract}

miR393 molecules are believed to regulate the expression of the auxin receptors of the TAAR clade. Considering the central role of auxin in the induction of somatic embryogenesis (SE) in plant explants cultured in vitro, the involvement of miR393 in the embryogenic transition of somatic cells has been hypothesised. To verify this assumption, the reporter, overexpressor and mutant lines in genes encoded MIR393 and TIR1/AFB proteins of the F-box family were analysed during SE in Arabidopsis. Expression profiling of MIR393a and MIR393b, mature miR393 and the target genes (TIRI, AFB1, AFB2, AFB3) were investigated in explants undergoing SE. In addition, the embryogenic potential of various genotypes with a modified activity of the MIR393 and TIRI/AFB targets was evaluated. The distinct increase in the accumulation of miR393 that was coupled with a notable down-regulation of TIRI and AFB2 targets was observed at the early phase of SE induction. Relevant to this observation, the GUS/ GFP monitored expression of MIR393, TIR1 and AFB2 transcripts was localised in explant tissue undergoing SE induction. The results suggest the miR393-mediated

Electronic supplementary material The online version of this article (doi:10.1007/s00425-016-2505-7) contains supplementary material, which is available to authorized users.

Małgorzata D. Gaj

mmdgaj@us.edu.pl

1 Department of Genetics, University of Silesia, Jagiellońska 28, 40-032 Katowice, Poland regulation of TIR1 and AFB2 during embryogenic transition induced in Arabidopsis and a modification of the explant sensitivity to auxin treatment is proposed as underlying this regulatory pathway.

Keywords Auxin receptors - AUXIN F-BOX PROTEIN $(A F B) \cdot$ miRNA - MIRNA - Somatic embryogenesis · TRANSPORT INHIBITORI (TIRI)

$\begin{array}{ll}\text { Abbreviations } \\ \text { AFB } & \text { Auxin F-box protein } \\ \text { 2,4-D } & \text { 2,4-Dichlorophenoxyacetic acid } \\ \text { E5 } & \text { Embryogenesis induction medium with auxin } \\ \text { E0 } & \text { Auxin-free induction medium } \\ \text { ORG } & \text { Organogenesis } \\ \text { DCL } & \text { Dicer-like } \\ \text { MIR } & \text { MICRO RNA gene } \\ \text { IZE } & \text { Immature zygotic embryo } \\ \text { SE } & \text { Somatic embryogenesis } \\ \text { TIR1 } & \text { Transport inhibitorl } \\ \text { ZE } & \text { Zygotic embryogenesis }\end{array}$

\section{Introduction}

Non-coding RNAs encoded by MIRNA genes, the so-called microRNAs (miRNAs), regulate gene expression by targeting mRNAs for degradation or translational repression (Axtell 2013). Transcription of MIRNA genes results in miRNA precursors (pri-miRNA) that are further proceeded to the final mature miRNA molecules through pre-miRNA intermediates (Bartel et al. 2004). The biogenesis of miRNA requires activity of multiple enzyme complexes and among them the RNase-III-like enzyme DICER- 
LIKE1 (DCL1) was indicated as playing a central role in the biogenesis of most of the miRNAs identified in plants (Reinhart et al. 2002). DCL1 interacts with other doublestranded RNA (dsRNA) binding proteins, HYPONASTIC LEAVES1 (HYL1) and the zinc-finger protein SERRATE (SE), to promote the efficient and accurate biogenesis of miRNA (Cuperus et al. 2010).

Besides DCL1, three other DCL enzymes (DCL2DCL4) are encoded in the genome of Arabidopsis thaliana (Schauer et al. 2013). In contrast to DCL1, which is involved in the biogenesis of MIRNA-encoded RNAs, the activity of DCL2-4 is related to the biogenesis of viral short interfering RNA (siRNA) and endogenous siRNA such as retrotransposon siRNA and trans-acting small interfering RNA (Xie et al. 2004). In addition, DCL4 was recently reported to process some of the "young", not conserved plant miRNA: miR822, miR839 and miR859 (Tsuzuki et al. 2014). DCL3 was revealed to cognate dsRNAs and produce the siRNAs that work in RNA-directed DNA methylation (Chapman and Carrington 2007).

In Arabidopsis, numerous $d c l l$ mutants that display a wide range of developmental defects were isolated (Schauer et al. 2002). Mutants of weak $d c l l$ alleles, $d c l l-7$ (sin 1-1: short integument1-1) and dcl1-9 (caf-1: carpel factory-1), have pleiotropic phenotypes including small leaves, late flowering and female sterility. In contrast, the null mutants, dcl1-5 (sus1-5: suspensor 1-5) and dcl1-6, are embryonically lethal (Suarez et al. 2015). In contrast to $D C L 1$, mutations in other $D C L$ genes do not produce defective phenotypes and double and triple mutants in $D C L 2, D C L 3$ and DCL4 were found to develop normally (Bouché et al. 2006).

The critical role of miRNAs in numerous biological and metabolic processes in plants has been documented, including zygotic embryogenesis (ZE) in which miRNAs were documented to be essential for the proper patterning and morphology of the embryos (Willmann et al. 2011; Vashisht and Nodine 2014; Seefried et al. 2014). During ZE in Arabidopsis, miRNAs were found to repress the embryo maturation process early in embryogenesis via the inhibition of the master regulators of ZE, including $L E A F Y$ COTYLEDON 2 (LEC2) and FUSCA3 (Willmann et al. 2011). This documented substantial impact of miRNAs on the control of $\mathrm{ZE}$ implicates the involvement of these molecules in the regulation of the somatic counterpart of $\mathrm{ZE}$, i.e. somatic embryogenesis (SE) induced in vitro in cultured explants (Zimmerman 1993). In line with this assumption, a global analysis of the SE-related transcriptomes of Oryza sativa (Chen et al. 2011a), hybrid yellow poplar (Li et al. 2012), Larix laptolerix (Zhang et al. 2012), Dimocarpus longan (Lin and Lai 2013) and Gossypium hirsutum (Yang et al. 2013) revealed numerous MIRNA/ miRNAs with differential expression levels. In addition, stem-loop qRT-PCR revealed differential accumulation of various miRNAs at different stages of SE in $C$. sinensis (Wu et al. 2011).

Among the candidate MIRNAs/miRNAs with a significant impact on SE induction, those related to auxin responses should be considered due to the central role of auxin signalling/metabolism in embryogenic induction in vitro (Jiménez 2005). In support of this assumption, auxin-related miRNA was identified in the embryogenic cultures of plants and among them miR393 was found in cotton (Wu et al. 2011; Yang et al. 2013). In Arabidopsis, analysis of over 190 MIRNA genes showed over twenty genes that were differentially regulated during SE induction and among them MIR393 genes, MIR393a and MIR393b, were found to be significantly up-regulated (K. Szyrajew, D. Bielewicz, Z. Szweykowska-Kulińska, A. Jarmłowski and M. D. Gaj, data not published). In Arabidopsis, MIRNA393 genes encode miR393 of the regulatory functions in the auxin responses that are associated with various developmental processes (Navarro et al. 2006; Si-Ammour et al. 2011). In planta, miR393 were indicated as targeting TIRI (TRANSPORT INHIBITORI), AFBI (AUXIN F-BOX PROTEIN1), $A F B 2$ and AFB3 (Navarro et al. 2006), which encode members of the TIR1/AFB clade of auxin receptors (TAARs) in the AFB family of plant F-box proteins (Mockaitis and Estelle 2008). Relevant to the essential role of miR393-mediated regulation in ZE of Arabidopsis (Nodine and Bartel 2010), the target mRNAs, TIR1, AFB and AUXIN RESPONSE FACTORS (ARFs) were detected as being active in the SE transcriptomes of cotton (Yang et al. 2013), longan (Lin and Lai 2013) and Arabidopsis (Gliwicka et al. 2013; Wickramasuriya and Dunwell 2015).

The aim of the study was to gain more insight into the role of miR393 in the auxin-related mechanisms that operate in SE induction. To this end, we used an embryogenic culture of Arabidopsis, a model plant that offers versatile tools for the functional analysis of genes (Provart et al. 2015). The expression level of MIR393, mature miR393 and the target genes (TIRI and $A F B$ ) were evaluated during the course of SE. In addition, the reporter, overexpressor and mutant lines were studied to reveal the relation between the activity of the studied genes and the embryogenic potential of the explants. The distinct increase in the accumulation of miR393 that was coupled with a notable down-regulation of TIRI and $A F B 2$ targets was observed at the early phase of SE induction. The study provides some evidence about the miR393-mediated regulation of embryogenic transition in Arabidopsis and a modification of the explant sensitivity to auxin treatment is assumed to be involved in this regulatory pathway. 


\section{Materials and methods}

\section{Plant material and growth conditions}

The Arabidopsis thaliana (L.) Heynh. Columbia (Col-0) parental genotype and the transgenic lines afb2-3, TIRIpro::EGFP, AFB1pro::EGFP, AFB2pro::EGFP, AFB3pro::EGFP were supplied by Nottingham Arabidopsis Stock Center (NASC). The T-DNA insertional mutants dcl1-6, dcl2-1 dcl3-1 dcl4-2 (hereafter noted dcl2/3/4), miR393a-1, mir393b-1, double mutant miR393a-1 miR393b-1 (hereafter noted mir393a/miR393b) and the reporter lines proMIR393a::GUS and proMIR393b::GUS, were kindly provided by Dr. F. Vazquez (University of Basel, Basel, Switzerland). The 35S::MIR393a, 35S::MIR393b and tirl-1 seeds were kindly provided by Prof. Mark Estelle (University of California at San Diego, USA). The characteristics of the transgenic genotypes that were used in the study are presented in Supplementary Table S1.

\section{In vitro culture of immature zygotic embryos (IZE) explants}

\section{Somatic embryogenesis induction}

Immature zygotic embryos (IZEs) of different genotypes were used as explants to establish an in vitro culture. Due to the embryonic lethality of the $d c l 1-6$ mutation, the IZEs that were homozygous for the mutation were isolated from the segregating $d c l 1-6 /+$ heterozygote. To induce SE, IZEs at the stage of green, fully developed cotyledons were cultured following a standard protocol (Gaj 2001). The standard medium used for SE induction (E5) contained a basal B5 medium (Gamborg et al. 1968) supplemented with $20 \mathrm{~g} \mathrm{~L}^{-1}$ sucrose, agar $\left(8 \mathrm{~g} \mathrm{~L}^{-1}\right)$ and $5 \mu \mathrm{M}$ of 2,4-D (2,4-dichlorophenoxyacetic acid) (2,4-D, Sigma). In some experiments, 2,4-D at additional concentrations $(0.1 ; 1.0$; 10 and $30 \mu \mathrm{M})$ was used. As a control culture, an auxinfree (E0) medium was used that resulted in the development of IZEs into seedlings.

\section{Induction of organogenesis (ORG)}

Shoot organogenesis (ORG), was induced in a culture of IZEs that was cultured for 7 days in a liquid callus induction medium (CIM) with $2.2 \mu \mathrm{M}$ 2,4-D and $0.2 \mu \mathrm{M}$ kinetin (Feldman and Marks 1986) and subsequently transferred to a solid shoot induction medium (SIM) supplemented with $0.5 \mu \mathrm{M}$ naphthalene acetic acid (NAA) and $4.4 \mu \mathrm{M}$ benzyl adenine (BAP) according to Kraut et al. (2011).
Plant growth and in vitro culture conditions

The plants used as the source of the IZE explants were grown in Jiffy-7 pots in a walk-in type green room at $21 \pm 1{ }^{\circ} \mathrm{C}$ under a $16 \mathrm{~h} / 8 \mathrm{~h}$ photoperiod of $100 \mu \mathrm{M} \mathrm{m}^{-2-}$ $\mathrm{s}^{-1}$ white, fluorescent light. The plant material that was grown in sterile conditions, i.e. in vitro cultured explants, were kept in a growth chamber at $21 \pm 1{ }^{\circ} \mathrm{C}$ under a $16 \mathrm{~h} /$ $8 \mathrm{~h}$ photoperiod of $40 \mu \mathrm{M} \mathrm{m}^{-2} \mathrm{~s}^{-1}$ white, fluorescent light.

\section{Evaluation of the culture morphogenic capacity}

The explant capacity for SE and ORG was evaluated in 21-day-old cultures and two parameters were calculatedefficiency (the percentage of explants that formed somatic embryos/shoots) and productivity (the average number of somatic embryos/shoots produced per explant). All of the culture combinations were evaluated in three replicates and at least 30 explants (ten explants/Petri dish) were analysed per one replicate.

\section{$R N A$ isolation and RT-qPCR analysis}

An RNAqueous kit (Ambion) was used to isolate total RNA from the IZE explants induced on an auxin (E5) and auxin-free (E0) medium at 0, 5, 10 and 15 days. Depending on the age of the culture, from 300 ( 0 day) to 100 (10 days) explants were used for RNA isolation. The concentration and purity of RNA was evaluated with a ND-1000 spectrophotometer (NanoDrop). To control DNA contamination, RNA was treated with RQ1 RNase-free DNase I (Promega) following the manufacturer's instructions. First strand cDNA was produced in a $20 \mathrm{~L}^{-1}$ reaction volume using a RevertAid First Strand cDNA Synthesis Kit (Fermentas). The product of reverse transcription was diluted with water at a $1: 4$ ratio and $2.5 \mathrm{~L}^{-1}$ of this solution was used for RT-qPCR reactions. RT-qPCR was carried out in a $10 \mathrm{~L}^{-1}$ reaction volume using a LightCycler ${ }^{\circledR}$ 480 SYBR Green I Master (Roche). The primers that were relevant to the genes being studied were used in the RT-PCR analysis (Supplementary Table S2).

A LightCycler 480 (Roche) real-time detection system was used under the following reaction conditions: denaturation one repeat of $10 \mathrm{~min}$ at $95{ }^{\circ} \mathrm{C}$, followed by 45 repeats of $10 \mathrm{~s}$ at $95{ }^{\circ} \mathrm{C}, 8 \mathrm{~s}$ at specific for primers temperature, $12 \mathrm{~s}$ at $72{ }^{\circ} \mathrm{C}$ and $5 \mathrm{~s}$ at $80{ }^{\circ} \mathrm{C}$. Denaturation for the melt curve analysis was conducted at $95{ }^{\circ} \mathrm{C}$ followed by $15 \mathrm{~s}$ at $65^{\circ} \mathrm{C}$ and $95{ }^{\circ} \mathrm{C}\left(0.1^{\circ} \mathrm{C} / \mathrm{s}\right.$ for fluorescence measurement $)$.

miRNA isolation, stem-loop RT-PCR and RT-qPCR analysis

A mirVana ${ }^{\mathrm{TM}}$ Kit was used to isolate miRNAs from the IZE explants induced on an auxin (E5) medium for 0, 5, 10 
and 15 days. Depending on the age of the culture, from 2000 (0 day) to 250 (10 days) explants were used for miRNA isolation. The concentration and purity of miRNA was evaluated with a ND-1000 spectrophotometer (NanoDrop). The oligonucleotides design, stem-loop RT and real time qPCR were performed according to Speth and Laubinger (2014). The primers sequences used in the study are listed in Supplementary Table S3.

Primary data analysis was performed using LightCycler Software 4.0 (Roche). Relative RNA levels were calculated and normalised to an internal control-the At4g27090 gene encoded 60S ribosomal protein (Thellin et al. 1999). In all of the analysed tissue samples, the control gene displayed a constant expression pattern with $\mathrm{Cp}=19 \pm 1$.

The plant tissues for the analysis of gene expression were produced in three biological replicates and two technical replicates of each repetition were carried out. The relative expression level was calculated using $2^{-\Delta \Delta C_{\mathrm{T}}}$ where $\Delta \Delta C_{\mathrm{T}} \quad$ represents $\Delta C_{\mathrm{T}}^{\text {reference }}$ condition $\Delta C_{\mathrm{T}}^{\text {compared condition }}$.

\section{Histological analysis}

All of the explants derived from the lines with GUS constructs were stained in a standard X-Gluc (5-bromo-4chloro-3-indolyl $\beta$-D-glucuronide cyclohexylammonium salt) (Sigma Aldrich) solution at $37{ }^{\circ} \mathrm{C}$ for $12 \mathrm{~h}$ as described by Jefferson et al. (1987). The expression of the GUS signal was inspected in the IZEs of the analysed lines using a Zeiss Stemi 2000-C microscope and images were saved as jpg files with an Axi-Vision Camera.

Green fluorescence protein (GFP) fluorescence was excited with a multiband argon laser at $100 \mathrm{mV}$ (Melles Griot BV) and a wavelength of $488 \mathrm{~nm}$. Image processing was performed using the FLUOVIEW computer program (Olympus, version 1.6).

\section{Data presentation and statistical analysis}

The figures show the averages with the standard deviations. To calculate the significant differences (at $P=0.05$ ) between the compared samples, the Student's $t$ test was applied.

\section{Results}

\section{DCL1 is required for somatic embryogenesis induction}

Two mutants that were impaired in the production of functional DCL proteins were analysed in terms of their embryogenic potential in vitro- $d c l l-6$ (Schauer et al.
2002) and the triple mutant $d c l 2 / 3 / 4$ (Garcia-Ruiz et al. 2010). It was found that the IZEs that were homozygous for dcll-6 mutation were arrested early in development (Fig. 1a, b). The embryos cultured on the E5 auxin medium were unable to induce SE and they produced a non-embryogenic callus in contrast to the Col-0 explants that developed somatic embryos efficiently (Fig. 1c, e). A decreased capacity for SE was also observed in the explants isolated from $d c l 1-6 /+$ plants; however, due to the recessive character of $d c l 1-6$ mutation, the embryogenic response of this culture was less impaired. In contrast to $d c l 1-6$, the $d c l 2 / 3 / 4$ mutant displayed a high embryogenic potential that was comparable to Col-0 culture (Fig. 1e).

These results clearly demonstrated that unlike DCL2, DCL3 and DCL4, the DCL1 function is required for SE induction. Thus, given the key role of this protein in the biogenesis of almost all miRNA, the essential functions of miRNA in embryogenic transition that is induced in vitro in Arabidopsis might be expected.

\section{MIR393 genes and their mature products are active in SE}

A survey of MIRNA gene transcripts in the embryogenic culture of Col-0 explants indicated a distinct up-regulation of MIR393a and MIR393b transcripts, which were accumulated up to 53 and 27 fold, respectively (Supplementary Fig. S1). To verify if the activation of MIR393 expression in the SE-induced explants may result in the production of mature miR393 molecules, stem-loop RT-qPCR analysis was performed. The analysis showed different levels of mature miR393 at all of the monitored time points $(0,5$ and 10 days) of the Col-0 embryogenic culture (Fig. 2a). Transient increase in the level of mature miR393 (up to 11 -fold) that was observed in the 5 days culture was associated with the early phase of SE induction, what is important for an auxin-related mechanism of SE induction.

A reporter line with promoter::GUS fusions was used to track the spatio-temporal pattern of the expression of MIR393a and MIR393b genes in the explants that were undergoing SE. The analysis showed that different patterns of GUS-monitored MIR393a and MIR393b expression were found in freshly isolated explants (0 day). A MIR393a GUS signal was observed in the cotyledons and vascular tissue of the hypocotyl part of the IZE (Fig. 2b), while a MIR393b signal was only detected in the cotyledons (Fig. 2c). In explants that were induced towards SE and treated with 2,4-D for 5 days, both of the MIR393 genes were found to be active in an apical part of the IZEs and an especially strong GUS signal was observed in the explant parts that are involved in embryogenic transition, i.e. in the adaxial parts of the cotyledons and in the vicinity of the shoot apical meristem (SAM) (Fig. 2d, e). In the 

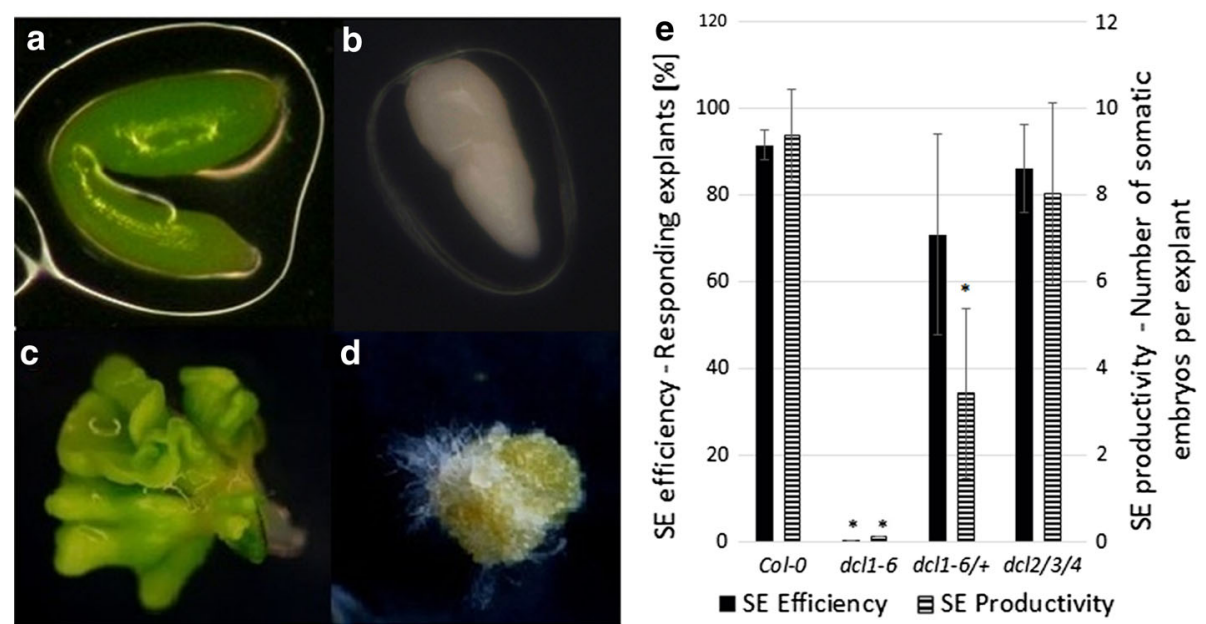

Fig. 1 The capacity for SE of $d c l$ mutants. Morphology of IZE explants of a highly embryogenic Col-0 genotype (a, c) and a dcll-6 mutant that was arrested in embryo development (b, d) cultured in vitro on an E5 medium for 0 day $(\mathbf{a}, \mathbf{b})$ and 21 days $(\mathbf{c}, \mathbf{d})$. Somatic embryos (c) and a non embryogenic callus (d) developed from Col-0 and a mutant explant, respectively. SE efficiency and SE productivity (e) of Col-0, dcll-6 and dcl2/3/4 mutants. Asterisks values significantly different from the parental Col-0 genotype $(P<0.05$; $n=3 \pm \mathrm{SD}$ )

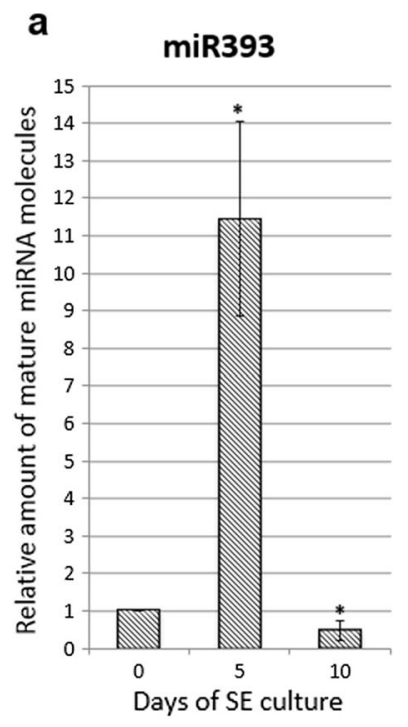

Fig. 2 Expression of miRNA/MIRNA in embryogenic culture. a Relative amount of mature miR393 molecules at 0,5 th and 10th day of Col-0 SE culture. Bars represent standard deviation $(n=3)$. Relative transcript level was normalised to the internal control (At4g27090) and calibrated to the 0 day of culture. Asterisks values significantly

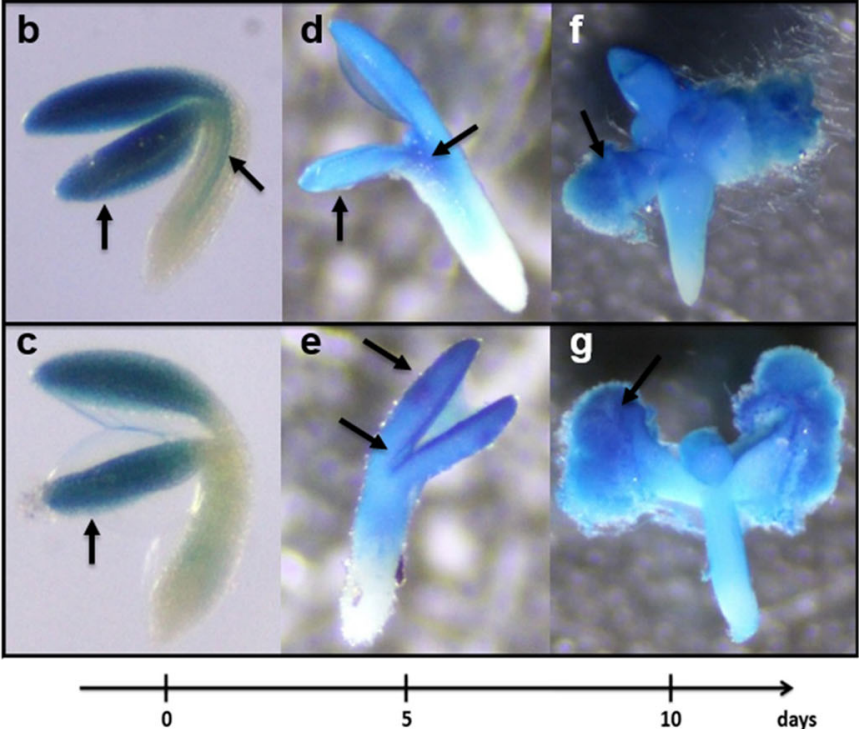

different from the 0 day of culture $(P<0.05 ; n=3 \pm \mathrm{SD})$. Expression patterns of GUS-monitored promoters of MIR393a (b, d, f) and $\operatorname{MIR} 393 b(\mathbf{c}, \mathbf{e}, \mathbf{g})$ genes at 0 day $(\mathbf{b}, \mathbf{c}), 5$ th day $(\mathbf{d}, \mathbf{e})$ and 10th day (f, g) of SE culture. Arrows indicate GUS signal in SEinvolved tissue (cotyledons and in the vicinity of SAM) advanced SE culture (10 days), MIR393 GUS signal was highly accumulated in the cotyledons- and SAM-derived embryogenic tissue developing somatic embryos (Fig. 2f, g).

Collectively, the results of the analyses of the mature miR393 and GUS-reporter lines showed that MIR393 genes are active in tissue undergoing embryogenic transition and that their mature transcripts are produced, which suggests the engagement of miR393 in the mechanism of SE induction in Arabidopsis.

\section{Functional analysis of MIR393 genes in SE}

To further validate the involvement of MIR393 genes in the induction of SE, transgenic lines with a contrasting activity of these genes were analysed, including T-DNA insertion 
mutants (miR393a, miR393b, miR393a/miR393b) and overexpressor lines $(35 S:: M I R 393 a, 35 S: \because M I R 393 b)$. The embryogenic potential of these genotypes was examined in vitro and the derived cultures were found to be significantly impaired in their capacity for SE in comparison to Col-0 (Fig. 3). We observed that both parameters, the frequency of the embryogenic explants and the average number of somatic embryos, were significantly reduced in the cultures derived from the mutants (Fig. 3a) and the overexpressor lines (Fig. 3b). The obtained results indicated that modulation of the level of miR393 molecules affects the embryogenic capacity of explants, thus suggesting the impact of miR393 on the regulation of SE induction in Arabidopsis.

\section{miR393 targets}

We investigated the expression of TIR1, AFB1, AFB2 and $A F B 3$ genes, which are targeted by miR393 in Arabidopsis (Navarro et al. 2006), in the IZE cultures induced on auxin (E5), auxin and cytokinin medium (ORG) and auxin-free (E0) medium using real-time qRT-PCR. The results of the analysis indicated diverse expression patterns of the target genes during SE (E5) and except for $A F B 3$, the level of three other miR393-targeted transcripts were significantly modulated in the embryogenic culture (Fig. 4). A downregulation of TIRI and $A F B 2$ at an early stage of SE induction (5 days) was observed and later on, a further
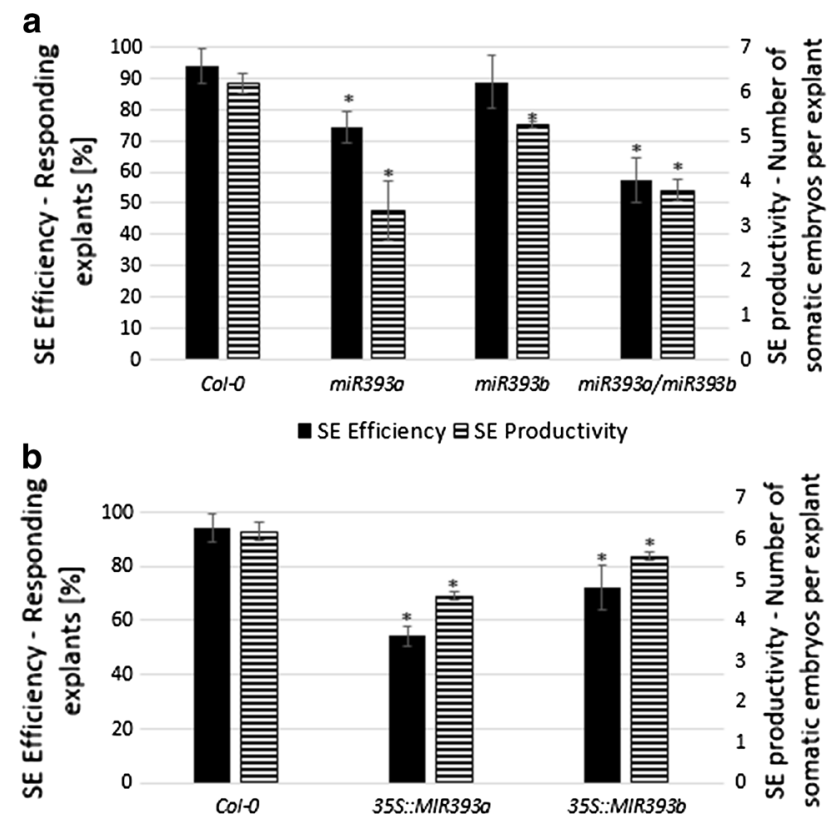

Fig. 3 SE efficiency and SE productivity of the cultures derived from a miR393 mutants (a) and the lines with an overexpression of MIR393 genes (b). IZE explants were cultured on an E5 medium. Asterisks values significantly different from the parental Col-0 genotype $(P<0.05 ; n=3 \pm \mathrm{SD})$ reduction of $A F B 2$ transcripts was evident while TIRI expression was increased at a more advanced SE stage (10 days). In contrast to TIR 1 and $A F B 2$, a gradual upregulation of $A F B 1$ was observed during $\mathrm{SE}$ and the gene transcripts were accumulated over eight-fold at more advanced SE (10 days).

In contrast to $\mathrm{SE}$, the expression profile of the auxin receptor genes in the ORG culture was similar to that observed in the control culture induced on a hormone-free (E0) medium. Thus, the significantly modulated transcript level of $T I R 1 / A F B 1 / A F B 2$ that was observed exclusively during SE appears to be associated with embryogenic transition and not to the auxin treatment per se.

A comparison of the levels of mature miR393 molecules and target transcripts in the embryogenic culture provided further support for a regulatory link between miR393 and TIR1 and AFB2 during SE (Fig. 5). We found that during an early stage of SE induction (5 days), the level of miR393 was opposite to TIR1 and $A F B 2$, thus implying that miR393 might down-regulate these targets during the early phase of SE induction. In a more advanced SE culture, the sharply decreasing level of miR393 was related to the accumulation of TIRI but not of $A F B 2$ transcripts.

To gain insight into the spatio-temporal expression pattern of TIR1 and $A F B 2$ genes in SE, the explants of the reporter lines (TIR1pro:EGFP, AFB2pro:EGFP) that were undergoing embryogenic induction on the E5 medium were inspected. No GFP signal was detected in the freshly

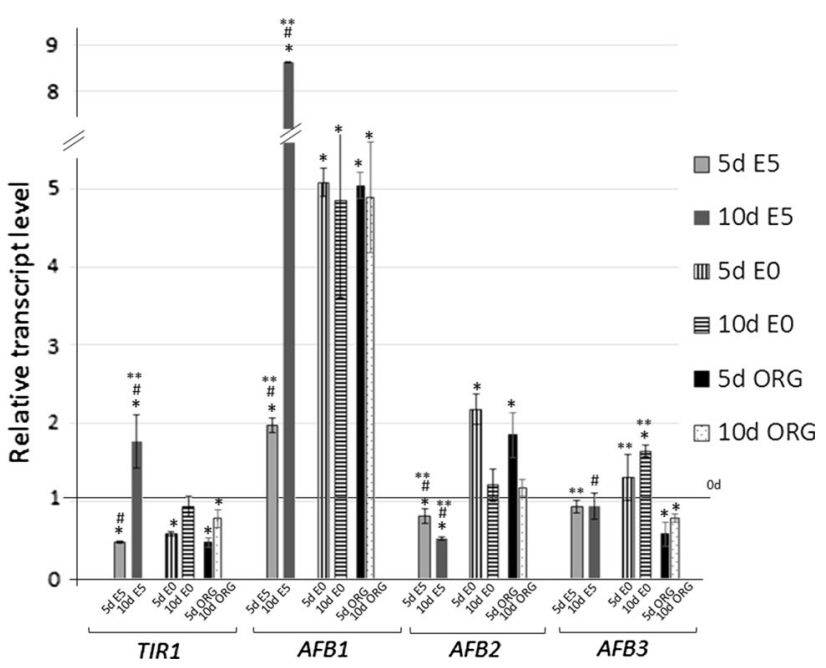

Fig. 4 Expression of miR393 target genes (TIR1, AFB1, AFB2 and $A F B 3$ ) in IZE explants of Col-0 cultured on an auxin-free (E0), auxin (E5) and auxin with cytokinin (ORG) medium. Relative transcript level was normalised to the internal control (At4g27090) and calibrated to the 0 day of culture. Bars represent standard deviation. Asterisks values significantly different from the 0 day of culture; hash values significantly different from the E0 culture of the same age; double asterisks values significantly different from the ORG culture of the same age $(P<0.05 ; n=3 \pm \mathrm{SD})$ 
isolated explants ( 0 day) but an intense signal reflecting the expression of $T I R 1$ and $A F B 2$ in the explant parts that are involved in the embryogenic transition (cotyledons, proximity of the shoot apical meristem, SAM) was observed at an early (5th day) and an advanced stage of SE (10th day) (Fig. 6). However, in contrast to TIR1, whose signal was distributed exclusively in the SE-associated parts of the explants, the GFP signal reflecting $A F B 2$ expression on the 5 th day of SE was also found in the basal part of the explants, which are not involved in SE. The results of the GFP analysis infer that TIRI and $A F B 2$ transcription is associated with the explant parts that are involved in SE induction. In contrast to TIRI and $A F B 2$, the GFP-signal of two other auxin receptor genes, $A F B 1$ and $A F B 3$, was not observed in the explant parts that are engaged in SE (Supplementary Fig. S3). In support for TIR1 and AFB2 involvement in SE, tirl-1 and $a f b 2-3$ insertional mutants were found to be significantly impaired in the embryogenic response and both the SE efficiency and productivity of the mutant cultures were significantly reduced (Fig. 7).

To further verify the hypothesis that miR393 regulates SE induction by targeting TIR1 and $A F B 2$ expression, the transcription of the miR393-target genes in an SE culture derived from transgenic lines with a disturbed level of miR393 was analysed (Fig. 8). The results, which show a reduction of TIRI and $A F B 2$ transcripts in the MIR393 overexpression lines and their accumulation in the miR393a/miR393b mutant, suggest a regulatory relation between miR393 and TIRI/AFB2 genes in SE. In contrast

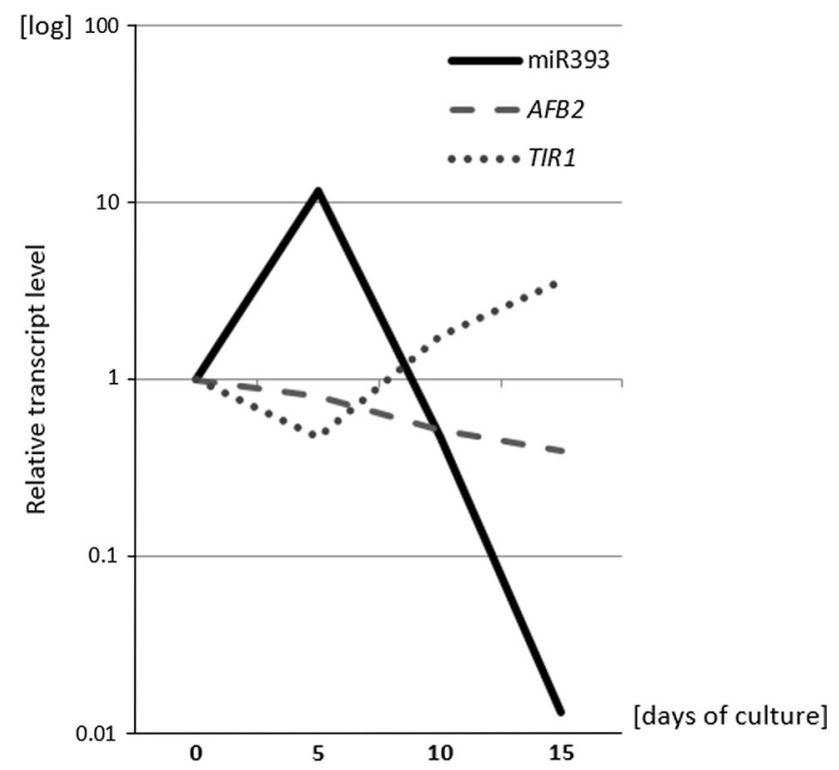

Fig. 5 Relative amount of mature miR393 molecules and transcript level of TIR1 and AFB2 genes at 0,5th, 10th and 15th day of SE culture of Col-0. Relative transcript level was normalised to the internal control (At4g27090) and calibrated to the 0 day of culture $(n=3)$ to TIRI and $A F B 2$, two other auxin receptor genes, $A F B 1$ and $A F B 3$, appear not to be targeted by miR393 in the embryogenic transition of somatic cells.

\section{miR393 affects explant sensitivity to auxin treatment}

Given that miR393 impacts SE induction through the regulation of the TIR 1 and $A F B 2$ genes that encode auxin receptors, we hypothesised that the biological function of miR393 in the control of embryogenic transition is the modulation of a tissue's sensitivity to exogenous auxin.

To verify this hypothesis, we analysed the embryogenic potential of explants with a disturbed accumulation of miR393 molecules and TIRI/AFB2 transcripts in relation to different concentrations of 2,4-D added to the SE induction medium. Explant treatment with $5 \mu \mathrm{M}$ of 2,4-D was the most effective for SE induction in Col-0 (WT) culture, which is in agreement with the optimised protocol for SE-induction in Arabidopsis (Gaj 2001) (Supplementary Fig. S2). Analysis of the cultures derived from the miR393 insertional lines indicated that these mutants show the highest embryogenic response under treatment with $1 \mu \mathrm{M}$ of $2,4-\mathrm{D}$, which is a concentration that is suboptimal for SE induction in Col-0 (Fig. 9a). In contrast to the miR393 mutants, the lines overexpressing MIR393 exhibited a significantly reduced sensitivity to auxin treatment and their explants formed somatic embryos efficiently in the presence of $30 \mu \mathrm{M}$ of $2,4-\mathrm{D}$ (Fig. 9b), which is a concentration that was over the one that was optimal for SE induction in the Col-0 culture. Like the MIR393 overexpression lines, the tirl-1 and afb2-3 mutant cultures exhibited an extremely reduced sensitivity to auxin treatment and their embryogenic response was significantly enhanced on the medium with the highest 2,4-D concentration (Fig. 9c).

Collectively, these results provide evidence that miR393 controls the embryogenic potential of the somatic tissues via the modulation of auxin sensitivity.

\section{Discussion}

The molecular mechanism that contributes to the embryogenic transition of somatic cells has recently being intensively investigated and auxin-related pathways have been emerging as playing an essential function in the regulation of $\mathrm{SE}$ induced in vitro in plant explants ( $\mathrm{Su}$ et al. 2009; Bai et al. 2013; Wójcikowska et al. 2013). The reports on the central role of the transcriptional regulation of auxin metabolism/signalling in SE induction implies that microRNAs, which are frequent regulators of transcription factor gene expression, might have a substantial impact on triggering embryogenic development in the somatic cells of plants. 
Fig. 6 GFP-monitored expression patterns of miR393target genes (TIR1 and $A F B 2$ ) in IZE explants cultured on an SE induction E5 medium. GFP signal (green) indicative for TIR1 (a-c) and $A F B 2(\mathbf{d}-\mathbf{f})$ at 0 day $(\mathbf{a}, \mathbf{d}), 5$ days $(\mathbf{b}, \mathbf{e})$ and 10 days $(\mathbf{c}, \mathbf{f})$ of SE culture. Red signal shows autofluorescence of chlorophyll, white arrows point to GFP signal localised at the explant areas involved in SE induction. Bar $500 \mu \mathrm{m}(\mathbf{a}, \mathbf{b}, \mathbf{d}$, e, 0 day and 5 days), $100 \mu \mathrm{m}(\mathbf{c}$, f, 10 days)
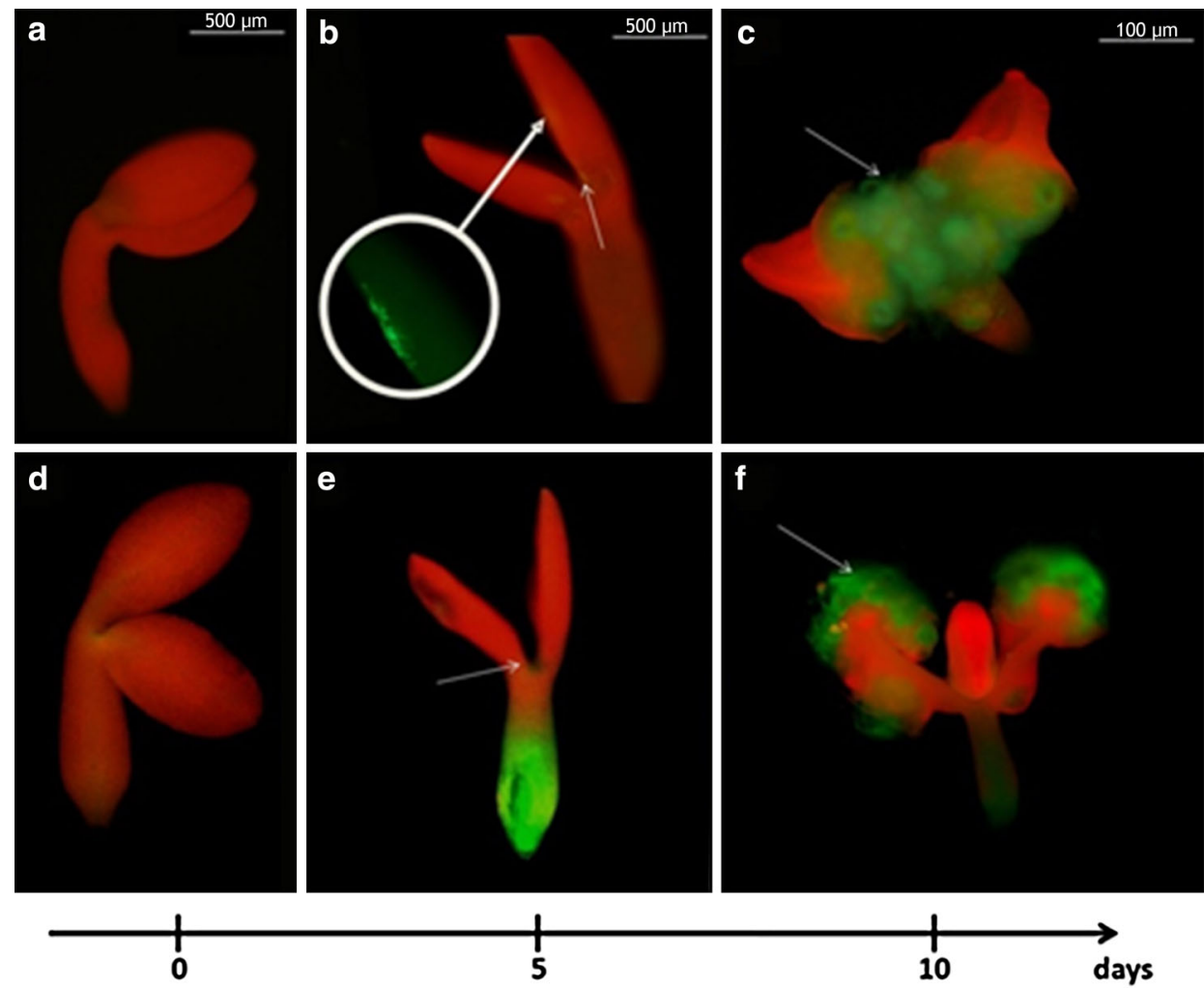

7

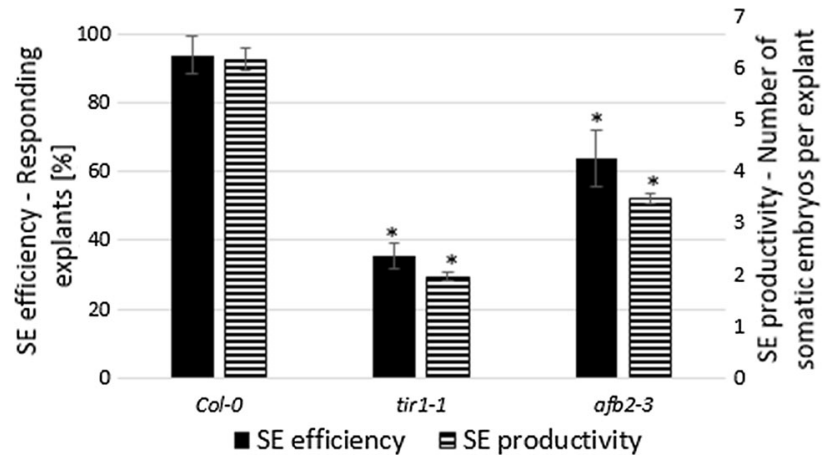

Fig. 7 SE efficiency and SE productivity of the tirl-1 and afb2-3 TIR 1 and AFB2 mutant explants cultured on an E5 medium. Asterisks values significantly different from the parental Col-0 genotype $(P<0.05 ; n=3 \pm \mathrm{SD})$

The results on the analysis of $d c l$ mutants provided in the present study support the postulate on the engagement of miRNA in SE regulation. It was observed that the null mutation in DCL1 (dcll-6), but not the mutations in other $D C L$ genes $(d c l 2 / 3 / 4)$, was found to totally eliminate the capacity of the explants for SE. Considering that DCL1, in contrast to the other three DCL proteins (DCL2-4) encoded in Arabidopsis genome, controls the processing of most of the miRNAs (Rogers and Chen 2013), the inability of the dcll mutant for SE infers a key role of miRNAs in the embryogenic transition of somatic cells. Similar to the present observation on the contrasting SE phenotypes of $d c l 1-6$ and $d c l 2 / 3 / 4$ mutants, $d c l 1$ null mutants in ZE were found to be highly defective in embryo development while a triple $d c l 2 / 3 / 4$ mutation did not affect the plant phenotype (Bouché et al. 2006; Nodine and Bartel 2010; Willmann et al. 2011; Seefried et al. 2014). Thus, the convergent effects of $d c l 1$ mutations in SE and ZE infer that miRNAs that is processed by DCL1 controls the embryogenic development of generative and vegetative cells. The key regulators of embryogenic development were indicated among the miRNA-controlled genes, including $L E C 2$, which has central functions in ZE and SE (Braybrook and Harada 2008; Ledwon and Gaj 2011; Willmann et al. 2011). $L E C 2$ was found to be under the indirect regulation of miR166, which is processed by DCL1 (Zhu et al. 2013; Jia et al. 2014). Thus, the de-regulation of the genes that regulate SE induction is assumed to account for the inability of the $d c l l$ mutant for embryogenic induction.

\section{miR393 impacts SE induction}

To gain more insights into the molecular mechanism of the miRNA-mediated regulation of SE induction, we found it to be reasonable to focus on the auxin-related regulators of gene transcription. Hence, the MIRNA393 genes that have a substantial role in the regulation of the auxin responses by targeting auxin receptors (Chen et al. 2011b; Iglesias et al. 


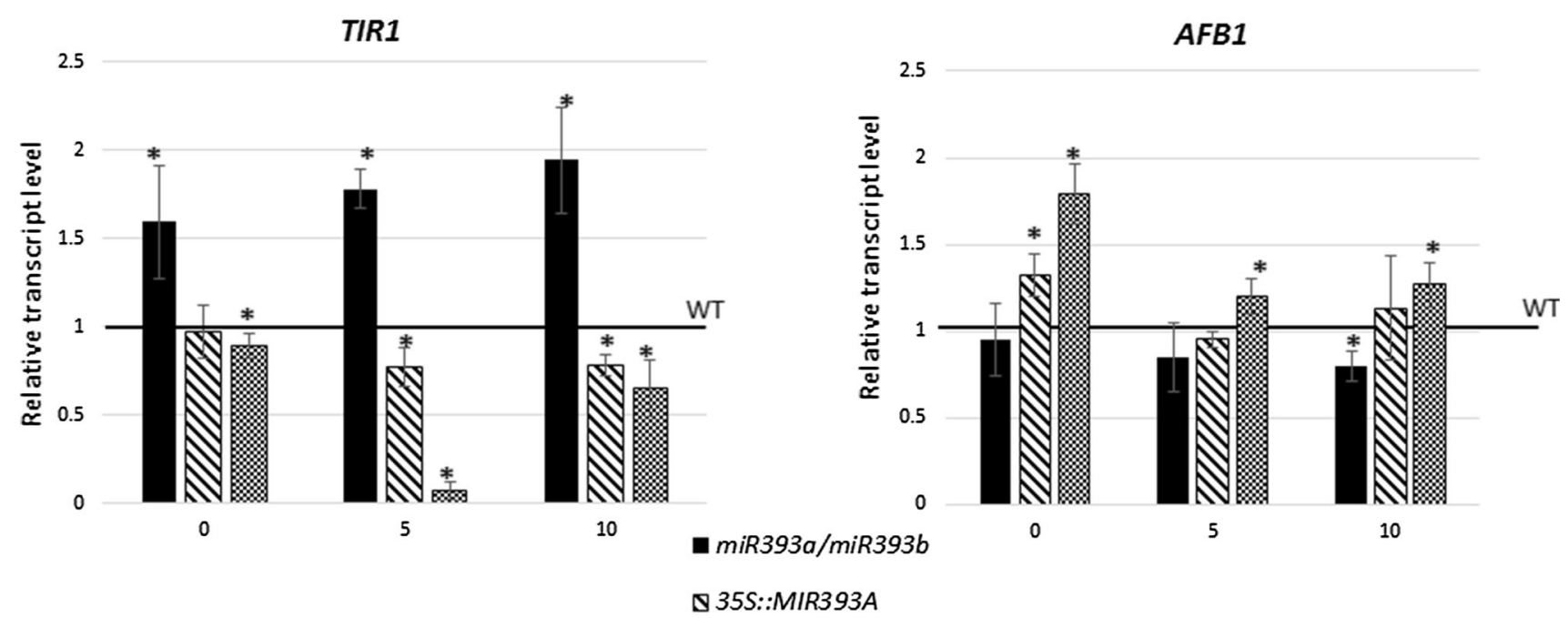

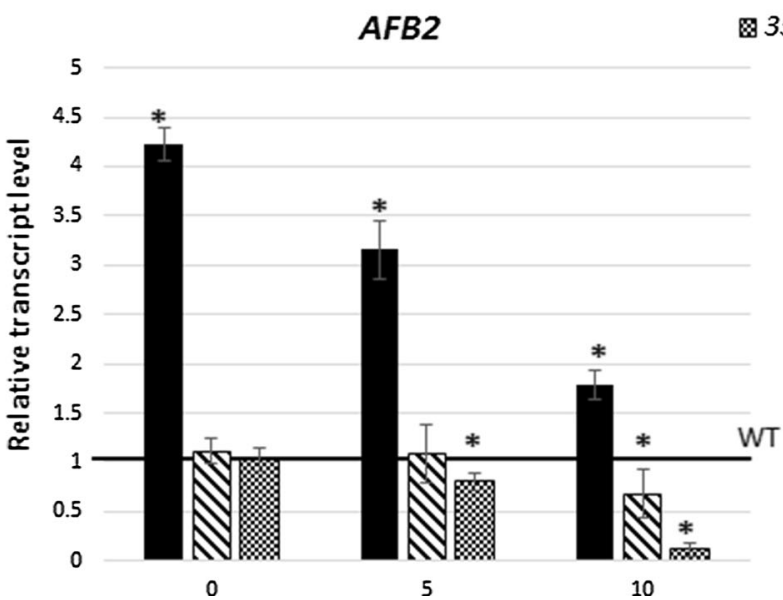

Fig. 8 Expression of miR393 target genes (TIR1, AFB1, AFB2 and $A F B 3)$ in IZE explants of miR393a/miR393b, 35S::MIR393a and $M I R 393 b$ lines. Relative transcript level was normalised to the internal control (At4g27090) and calibrated to the WT culture. Bars

2014) were subjected to the analysis in the present study. Our observation that within numerous MIRNA genes with a significantly up-regulated transcription in SE, the $M I R$ NA393a and MIRNA393b primary transcripts were highly accumulated (K. Szyrajew, D. Bielewicz, Z. Szweykowska-Kulińska, A. Jarmołowski and M. D. Gaj, data not shown) supports the engagement of these genes in the regulation of embryogenic transition. The contribution of both of the MIR393 genes encoded in the Arabidopsis genome to miR393 production might be expected considering that stress- and auxin-related functions, which have been reported for MIRNA393a and MIRNA393b, respectively, are believed to control embryogenic transition in the somatic tissue of plants (Navarro et al. 2006; Chen et al. 2011b). The activity of MIRNA393a and MIRNA393b in the SE-involved parts (cotyledons and in the vicinity of the shoot apical meristem) of the explants was shown using
GUS-reporter lines, which further supports the involvement of the MIR393 genes in SE induction. The results of the GUS and the qRT-PCR monitored gene expression also indicate the high activity of the MIR393 genes in the early (5 days) and the advanced (10 days) phase of SE induction. In contrast, a large accumulation of mature miR393 was observed exclusively at day five of SE while a drastic decrease in miR393 was found in the most advanced culture (10 days). The post-transcriptional regulation that is involved in the production of functional miRNA in plants and animals may be considered to explain this apparent discrepancy in the levels of the primary and mature miRNA (Rüegger and Großhans 2012; Zielezinski et al. 2015). Due to the complex, multi-step and spatio-temporal control of miRNA biogenesis, the primary MIRNA transcripts and the relevant mature miRNA frequently appear to not be related (Obernosterer et al. 2006; Thomson et al. 

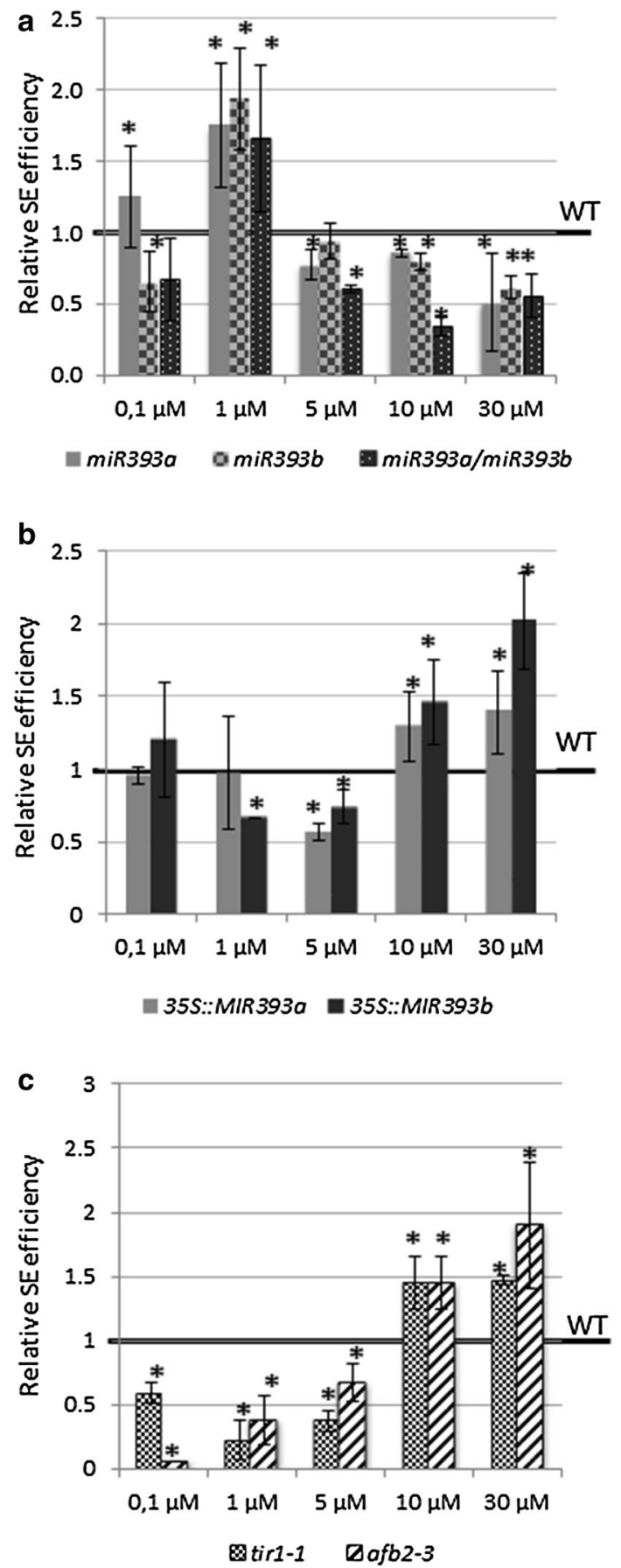

Fig. 9 SE efficiency of the transgenic lines with a different activity of miR393 due to an insertion in MIRNA genes, miR393a; miR393b, miR393ab (a), overexpression of MIR393 genes, 35S::MIR393a, $35 S:: M I R 393$ (b) and insertion in miR393-targeted genes (c), TIR1 and AFB2-3 genes (tir1-1, afb2-3). IZE explants were cultured on an $\mathrm{SE}$ induction medium with different concentration of 2,4-D. Asterisks values significantly different from the parental Col-0 genotype cultured on the same medium $(P<0.05 ; n=3 \pm \mathrm{SD})$

2006; Szweykowska-Kulinska et al. 2013). However, in spite of the complexity of the spatio-temporal control of miRNA biogenesis, a defined SE-specific level of the primary MIR393 transcripts seems to be required for the efficient induction of SE because the de-regulation of the MIR393 gene expression via the overexpression and down regulation of MIR393a and MIR393b resulted in a significantly defective embryogenic potential of the culture (present results).

\section{miR393 targets auxin receptor genes TIRI and $A F B 2$ during $\mathrm{SE}$ induction}

The results of the present study, which is based on gene expression profiling and an analysis of the mutant/reporter lines, suggest that miR393 is likely to impact SE induction via the regulation of two of TAAR genes, TIRI and $A F B 2$. Considering that expression of TAAR genes is not responsive to auxin (Parry et al. 2009), the significant modulation of TIRI and $A F B 2$ transcripts observed in the SE culture (present results) appears to reflect the involvement of miR393 in embryogenic transition. Both genes encode auxin receptors, which are positive regulators of auxin signalling and they are expected to play more important roles in plant development than other members of TAAR clade (Parry et al. 2009; Wang and Estelle 2014). TIR1 and $A F B 2$ were indicated to be targeted by miR393 in root development in Arabidopsis (Parry et al. 2009) and during salt stress in Arabidopsis (Iglesias et al. 2014) and O. sativa (Xia et al. 2012). The postulate on the miR393-controlled activity of TIRI and $A F B 2$ in SE induction in Arabidopsis, down-regulation of these genes possibly via miR393 was also observed during SE in cotton, which is relevant to the present study (Yang et al. 2012, 2013).

The present results showed that in contrast to TIRI and $A F B 2$, two other genes of the auxin receptors of the TAAR family, $A F B 1$ and $A F B 3$, do not seem to be regulated by miR393 in SE. Even though the translational level of $A F B 1$ regulation by miR393 may be considered (Navarro et al. 2006), the engagement of $A F B 1$ in SE is of a low probability since no GFPmonitored transcription of $A F B 1$ was detected in the explant parts that were undergoing SE induction (Supplementary Fig. S3). Additionally, the contribution of $A F B 3$ to the mechanism of SE induction appears to be doubtful considering the stable expression of this gene in the SE culture and the results of the AFB3pro::EGFP reporter line analysis. Moreover, the involvement of $A F B 3$ in SE seems to be unlikely due to the fact that the gene was indicated to control the root responses to nitrate while its function in the regulation of $\mathrm{ZE}$, the zygotic counterpart of SE, was not reported (Vidal et al. 2010; Si-Ammour et al. 2011).

The drastic differences that were found between the TIR1/AFBs receptors in their affinity to both AUX/IAA 
proteins and auxin imply that a specific combination of different F-box receptors may regulate various auxin-regulated processes including SE (Calderón Villalobos et al. 2012). Importantly for the 2,4-D-induced SE, TAAR proteins also were demonstrated to differ in their binding affinity to auxin herbicides, and, e.g., a strong affinity of AFB5 to picloram was reported (Calderón Villalobos et al. 2012). Thus, the recognition of TAAR receptors with the highest affinity to 2,4-D, which is commonly used to induce SE, would be helpful in the identification of the miR393-targeted auxin receptors that operate in SE induction.

\section{miR393-mediated regulation of receptor genes TIRI and $A F B 2$ controls tissue sensitivity to auxin}

miR393 was recently suggested to target the auxin receptors TIR1 and AFB2 during SE induction (Yang et al. 2013). Thus, we hypothesised that miR393 contributes to the SE induction mechanism via the modulation of tissue sensitivity to auxin. In support of this assumption, the embryogenic response of explant tissue was found to be related to the level of MIRNA gene expression and the concentration of 2,4-D that was used in the SE induction medium. Accordingly, the mutations in MIRNA393 genes resulted in a hypersensitivity to auxin while the overexpression of MIR393 transcripts led to a contrasting phenotype. Consistent with these results, the explants isolated from tirl-1 and afb2-3 mutants were indicated to display a hyposensitivity to auxin treatment. A similar relation between the overexpression of MIR393 and tissue sensitivity to auxin was also observed in Oryza sativa in planta and a high miR393 activity was suggested as causing the decreased sensitivity of seedlings to 2,4-D that resulted in the dramatic inhibition of the primary root elongation (Bian et al. 2012).

Conclusively, we assumed that miR393 might influence the embryogenic potential of explant cells via the auxin signalling pathway and the modification of a cell's sensitivity to auxin.

\section{Stress-related functions of miR393 in SE}

Recently, it has become apparent that the auxin responses that accompany SE induction are closely linked to the stress responses that are activated during the embryogenic transition of somatic cells of plants (Fehér 2015). In support of the stress-related mechanism of SE induction, the enhanced production of reactive oxygen species (ROS) that was observed after 2,4-D treatment and the recently uncovered ROS-mediated modifications of the cytoskeleton structure and peroxisome dynamics, might be considered to contribute to SE induction (Pasternak et al. 2002;
Ötvös et al. 2005; Rodríguez-Serrano et al. 2014). Relevant to the notion about the role of stress-responses in SE induction, several reports have documented the involvement of miR393 in the responses of plants to biotic and abiotic stresses (Navarro et al. 2006; Chen et al. 2015). A recent report on the mir393 mutants has provided a clue for a possible role of miR393 in the control of the stress-related pathway that is activated during SE induction (Iglesias et al. 2014). Mutants with a reduced activity of miR393 were found to display an increased production of ROS, which was coupled with the repressed metabolism of the antioxidants, while the tirlafb2 mutant displayed the opposite phenotype (Iglesias et al. 2014). In conclusion, the present results on the miR393-mediated control of SE induction provide convincing evidence that the function of miR393 in the embryogenic transition of somatic cells seems to be related to the integration of the environmental cues and the maintenance of a proper homeostasis of auxin signalling as was proposed for in planta development (Windels and Vazquez 2011; Windels et al. 2014).

Further analyses are required to define other components of the miR393-regulated network that underlie the developmental plasticity of plant cells that is released under in vitro conditions. The complex feedback regulations between the miR393 and TAAR proteins and the tissuespecific functions of the auxin signalling components might be expected during SE induction as was indicated in the developmental processes in planta (Si-Ammour et al. 2011; Chen et al. 2015; Wang and Estelle 2014).

Author contribution statement MDG and AMW conceived and designed research. AMW conducted the experiments. AMW and MDG analysed the data and wrote the manuscript. Both of the authors read and approved the manuscript.

Acknowledgments This work was supported by a research grant from the National Science Centre in Poland (OPUS5 2013/09/B/NZ2/ 03233).

\section{Compliance with ethical standards}

Conflict of interest The authors declare that they have no conflict of interest.

Open Access This article is distributed under the terms of the Creative Commons Attribution 4.0 International License (http://creative commons.org/licenses/by/4.0/), which permits unrestricted use, distribution, and reproduction in any medium, provided you give appropriate credit to the original author(s) and the source, provide a link to the Creative Commons license, and indicate if changes were made.

\section{References}

Axtell MJ (2013) Classification and comparison of small RNAs from plants. Annu Rev Plant Biol 64:137-159 
Bai B, Su YH, Yuan J, Zhang XS (2013) Induction of somatic embryos in Arabidopsis requires local YUCCA expression mediated by the down-regulation of ethylene biosynthesis. Mol Plant 6:1247-1260

Bartel DP, Lee R, Feinbaum R (2004) MicroRNAs: genomics, biogenesis, mechanism, and function genomics: the MIRNA genes. Cell 116:281-297

Bian H, Xie Y, Guo F et al (2012) Distinctive expression patterns and roles of the miRNA393/TIR1 homolog module in regulating flag leaf inclination and primary and crown root growth in rice (Oryza sativa). New Phytol 196:149-161

Bouché N, Lauressergues D, Gasciolli V, Vaucheret H (2006) An antagonistic function for Arabidopsis DCL2 in development and a new function for DCL4 in generating viral siRNAs. EMBO J 25:3347-3356. doi:10.1038/sj.emboj.7601217

Braybrook S, Harada J (2008) LECs go crazy in embryo development. Trends Plant Sci 13:624-630. doi:10.1016/j.tplants.2008.09.008

Calderón Villalobos IL, Lee S et al (2012) A combinatorial TIR1/ AFB-Aux/IAA co-receptor system for differential sensing of auxin. Nat Chem Biol 8:477-485. doi:10.1038/nchembio.926

Chapman EJ, Carrington JC (2007) Specialization and evolution of endogenous small RNA pathways. Nat Rev Genet 8:884-896. doi:10.1038/nrg2179

Chen C-J, Liu Q, Zhang Y-C et al (2011a) Genome-wide discovery and analysis of microRNAs and other small RNAs from rice embryogenic callus. RNA Biol 8:538-547. doi:10.4161/rna.8.3. 15199

Chen ZH, Bao ML, Sun YZ et al (2011b) Regulation of auxin response by miR393-targeted transport inhibitor response protein 1 is involved in normal development in Arabidopsis. Plant Mol Biol 77:619-629. doi:10.1007/s11103-011-9838-1

Chen Z, Hu L, Han N et al (2015) Overexpression of a miR393resistant form of Transport Inhibitor Response Protein 1 (mTIR1) enhances salt tolerance by increased osmoregulation and $\mathrm{Na}+$ exclusion in Arabidopsis thaliana. Plant Cell Physiol 56:73-83. doi:10.1093/pcp/pcu149

Cuperus JT, Carbonell A, Fahlgren N et al (2010) Unique functionality of $22 \mathrm{nt}$ miRNAs in triggering RDR6-dependent siRNA biogenesis from target transcripts in Arabidopsis. Mol Cell 17:997-1003. doi:10.1038/nsmb.1866

Fehér A (2015) Somatic embryogenesis-stress-induced remodeling of plant cell fate. Biochim Biophys Acta Gene Regul Mech 1849:385-402. doi:10.1016/j.bbagrm.2014.07.005

Gaj MD (2001) Direct somatic embryogenesis as a rapid and efficient system for in vitro regeneration of Arabidopsis thaliana. Plant Cell Tissue Organ Cult 64:39-46. doi:10.1023/A:1010679614721

Gamborg OL, Miller RA, Ojima K (1968) Nutrient requirement of suspension culture of soybean root cells. Exp Cell Res 50:151-158

Garcia-Ruiz H, Takeda A, Chapman EJ et al (2010) Arabidopsis RNA-dependent RNA polymerases and dicer-like proteins in antiviral defense and small interfering RNA biogenesis during Turnip Mosaic Virus infection. Plant Cell 22:481-496. doi:10. 1105/tpc. 109.073056

Gliwicka M, Nowak K, Balazadeh S et al (2013) Extensive modulation of the transcription factor transcriptome during somatic embryogenesis in Arabidopsis thaliana. PLoS One 8:e69261. doi:10.1371/journal.pone.0069261

Iglesias MJ, Terrile MC, Windels D et al (2014) MiR393 regulation of auxin signaling and redox-related components during acclimation to salinity in Arabidopsis. PLoS One 9:e107678. doi:10. 1371/journal.pone.0107678

Jefferson RA, Kavanagh TA, Bevan MW (1987) GUS fusions: $\beta$ glucuronidase as a sensitive and versatile gene fusion marker in higher plants. EMBO J 6:3901-3907
Jia H, Suzuki M, Mccarty DR (2014) Regulation of the seed to seedling developmental phase transition by the LAFL and VAL transcription factor networks. WIREs Dev Biol 3:135-145. doi:10.1002/wdev.126

Jiménez VM (2005) Involvement of plant hormones and plant growth regulators on in vitro somatic embryogenesis. Plant Growth Regul 47:91-110

Ledwoń A, Gaj MD (2011) LEAFY COTYLEDON1, FUSCA3 expression and auxin treatment in relation to somatic embryogenesis induction in Arabidopsis. Plant Growth Regul 65:157-167. doi:10.1007/s10725-011-9585

Li T, Chen J, Qiu S et al (2012) Deep sequencing and microarray hybridization identify conserved and species-specific microRNAs during somatic embryogenesis in hybrid yellow poplar. PLoS One 7:1-12. doi:10.1371/journal.pone.0043451

Lin Y, Lai Z (2013) Comparative analysis reveals dynamic changes in miRNAs and their targets and expression during somatic embryogenesis in Longan (Dimocarpus longan Lour.). PLoS One 8:15-18. doi:10.1371/journal.pone.0060337

Mockaitis K, Estelle M (2008) Auxin receptors and plant development: a new signaling paradigm. Annu Rev Cell Dev Biol 24:55-80. doi:10.1146/annurev.cellbio.23.090506.123214

Navarro L, Dunoyer P, Jay F et al (2006) A plant miRNA contributes to antibacterial resistance by repressing auxin signaling. Science 312:436-439. doi:10.1126/science. 1126088

Nodine MD, Bartel DP (2010) MicroRNAs prevent precocious gene expression and enable pattern formation during plant embryogenesis. Genes Dev 24:2678-2692. doi:10.1101/gad.1986710

Obernosterer G, Leuschner PJF, Alenius M, Martinez J (2006) Posttranscriptional regulation of microRNA expression. RNA 12:1161-1167

Ötvös K, Pasternak TP, Miskolczi P et al (2005) Nitric oxide is required for, and promotes auxin-mediated activation of, cell division and embryogenic cell formation but does not influence cell cycle progression in alfalfa cell cultures. Plant J 43:849-860. doi:10.1111/j.1365-313X.2005.02494.x

Parry G, Calderon-Villalobos LI, Prigge M et al (2009) Complex regulation of the TIR1/AFB family of auxin receptors. Proc Natl Acad Sci USA 106:22540-22545. doi:10.1073/pnas. 0911967106

Pasternak TP, Prinsen E, Ayaydin F et al (2002) The role of auxin, $\mathrm{pH}$, and stress in the activation of embryogenic cell division in leaf protoplast-derived cells of alfalfa. Plant Physiol 129:1807-1819. doi:10.1104/pp.000810

Provart NJ, Alonso J, Assmann SM et al (2015) 50 years of Arabidopsis research: highlights and future directions. New Phytol. doi:10.1111/nph.13687

Reinhart BJ, Weinstein EG, Rhoades MW, Bartel B, Bartel DP (2002) MicroRNAs in plants. Genes Dev 16:1616-1626

Rodríguez-Serrano M, Pazmiño DM, Sparkes I et al (2014) 2,4Dichlorophenoxyacetic acid promotes S-nitrosylation and oxidation of actin affecting cytoskeleton and peroxisomal dynamics. J Exp Bot 65:4783-4793. doi:10.1093/jxb/eru237

Rogers K, Chen X (2013) Biogenesis, turnover, and mode of action of plant microRNAs. Plant Cell 25:2383-2399. doi:10.1105/tpc. 113.113159

Rüegger S, Großhans H (2012) MicroRNA turnover: when, how, and why. Trends Biochem Sci 37:436-446. doi:10.1016/j.tibs.2012. 07.002

Schauer SE, Jacobsen SE, Meinke DW, Ray A (2002) DICER-LIKE1: blind men and elephants in Arabidopsis development. Trends Plant Sci 7:487-491

Seefried WF, Willmann MRR, Clausen RL, Jenik PD (2014) Global regulation of embryonic patterning in Arabidopsis by microRNAs. Plant Physiol 165:670-687. doi:10.1104/pp.114.240846 
Si-Ammour Windels D, Arn-Bouldoires E et al (2011) miR393 and secondary siRNAs regulate expression of the TIR1/AFB2 auxin receptor clade and auxin-related development of Arabidopsis leaves. Plant Physiol 157:683-691. doi:10.1104/pp.111.180083

Speth C, Laubinger S (2014) Rapid and parallel quantification of small and large RNA species. In: Staiger D (ed) Plant circadian networks methods and protocols. Springer, New York, pp 93-106

Su YH, Zhao XY, Liu YB et al (2009) Auxin-induced WUS expression is essential for embryonic stem cell renewal during somatic embryogenesis in Arabidopsis. Plant J 59:448-460. doi:10.1111/j.1365-313X.2009.03880.x

Suarez IP, Burdisso P, Benoit MPMH et al (2015) Induced folding in RNA recognition by Arabidopsis thaliana DCL1. Nucleic Acids Res 43:6607-6619. doi:10.1093/nar/gkv627

Szweykowska-Kulińska Z, Jarmolowski A, Vazquez F (2013) The crosstalk between plant microRNA biogenesis factors and the spliceosome. Plant Signal Behav 8:1-6. doi:10.4161/psb.26955

Thellin O, Zorzi W, Lakaye B, De Borman B, Coumans B, Hennen G, Grisar T, Igout A, Heinen E (1999) Housekeeping genes as internal standards: use and limits. J Biotechnol 75:291-295

Thomson JM, Newman M, Parker JS et al (2006) Extensive posttranscriptional regulation of microRNAs and its implications for cancer. Genes Dev 20:2202-2207. doi:10.1101/gad.1444406

Tsuzuki M, Takeda A, Watanabe Y (2014) Recovery of dicer-like 1late flowering phenotype by miR172 expressed by the noncanonical DCL4-dependent biogenesis pathway. RNA 20:1320-1327. doi:10.1261/rna.044966.114

Vashisht D, Nodine MD (2014) MicroRNA functions in plant embryos. Biochem Soc Trans 42:352-357. doi:10.1042/ BST20130252

Vidal EA, Araus V, Lu C et al (2010) Nitrate-responsive miR393/ $A F B 3$ regulatory module controls root system architecture in Arabidopsis thaliana. Proc Natl Acad Sci USA 107:4477-4482. doi:10.1073/pnas.0909571107

Wang R, Estelle M (2014) Diversity and specificity: auxin perception and signaling through the TIR1/AFB pathway. Curr Opin Plant Biol 21:51-58. doi:10.1016/j.pbi.2014.06.006

Wickramasuriya AM, Dunwell JM (2015) Global scale transcriptome analysis of Arabidopsis embryogenesis in vitro. BMC Genom 16:301. doi:10.1186/s12864-015-1504-6

Willmann MR, Mehalick AJ, Packer RL, Jenik PD (2011) MicroRNAs regulate the timing of embryo maturation in Arabidopsis. Plant Physiol 155:1871-1884. doi:10.1104/pp.110.171355

Windels D, Vazquez F (2011) miR393: integrator of environmental cues in auxin signaling? Plant Signal Behav 6:1672-1675. doi:10.4161/psb.6.11.17900
Windels D, Bielewicz D, Ebneter M et al (2014) miR393 is required for production of proper auxin signalling outputs. PLoS One 9:e95972. doi:10.1371/journal.pone.0095972

Wójcikowska B, Jaskóła K, Gąsiorek P et al (2013) LEAFY COTYLEDON2 (LEC2) promotes embryogenic induction in somatic tissues of Arabidopsis, via YUCCA-mediated auxin biosynthesis. Planta 238:425-440. doi:10.1007/s00425-013$1892-2$

Wu XM, Liu MY, Ge XX et al (2011) Stage and tissue-specific modulation of ten conserved miRNAs and their targets during somatic embryogenesis of Valencia sweet orange. Planta 233:495-505. doi:10.1007/s00425-010-1312-9

Xia K, Wang R, Ou X et al (2012) OsTIR1 and OsAFB2 downregulation via OsmiR393 overexpression leads to more tillers, early flowering and less tolerance to salt and drought in rice. PLoS One 7:1-10. doi:10.1371/journal.pone.0030039

Xie Z, Johansen LK, Gustafson AM et al (2004) Genetic and functional diversification of small RNA pathways in plants. PLoS Biol 2:e104. doi:10.1371/journal.pbio.0020104

Yang X, Zhang X, Yuan D et al (2012) Transcript profiling reveals complex auxin signalling pathway and transcription regulation involved in dedifferentiation and redifferentiation during somatic embryogenesis in cotton. BMC Plant Biol 12:110. doi:10.1186/1471-2229-12-110

Yang X, Wang L, Yuan D et al (2013) Small RNA and degradome sequencing reveal complex miRNA regulation during cotton somatic embryogenesis. J Exp Bot 64:1521-1536. doi:10.1093/ jxb/ert013

Zhang J, Zhang S, Han S et al (2012) Genome-wide identification of microRNAs in larch and stage-specific modulation of 11 conserved microRNAs and their targets during somatic embryogenesis. Planta 236:647-657. doi:10.1007/s00425-012-1643-9

Zhu H, Zhou Y, Castillo-gonzález C et al (2013) Bi-directional processing of pri-miRNAs with branched terminal loops by Arabidopsis Dicer-like1. Nat Struct Mol Biol 20:1106-1115. doi:10.1038/nsmb.2646

Zielezinski A, Dolata J, Alaba S et al (2015) mirEX 2.0-an integrated environment for expression profiling of plant microRNAs. BMC Plant Biol 15:144. doi:10.1186/s12870-015-0533-2

Zimmerman J (1993) Somatic embryogenesis: a model for early development in higher plants. Plant Cell 5:1411-1423. doi:10. 1105/tpc.5.10.1411 